Recibido: 22-noviembre-2013

Aceptado: 28-noviembre-2013

\title{
LA POÉTICA DE LAS IDEAS EN EL ECUADOR LECTURAS UNIVERSALES DE HOMBRES PARTICULARES
}

GALO CEVALLOS RUEDA

FLACSO

Colegio Alemán (Quito) 


\section{RESUMEN}

La poética de las ideas en el Ecuador. Lecturas universales de hombres particulares, es un ensayo filosófico de interpretación cultural, que busca poner de manifiesto los esplendores filosóficos y artísticos del Ecuador desde una hermenéutica simbólica. Resaltando los aportes en la comprensión de la universalidad del hombre ecuatoriano y latinoamericano, sosteniendo un humanismo que reinterpreta el pasado cultural retratando a personajes del pensamiento y el arte que dejaron una impronta de universalidad y versatilidad comprensiva, que los catapulta como hermeneutas poéticos de la cultura Latinoamérica, poniendo en duda y reconsiderando la seudohistoria universal de sesgo eurocéntrico. El pensador Benjamín Carrión, el poeta Jorge Carrera Andrade y el escultor colonial Caspicara. Exponentes magníficos de una mentalidad espiritual original y trascendente. Nos muestran en su qué hacer las fuentes profundas de una cultura activamente constructiva y de fuente estética.

Palabras clave: Mircea Eliade, Benjamín Carrión, mito, patria, eurocentrismo, hermenéuticas reductivas.

\section{ABSTRACT}

The poetic ideas in Ecuador. Universal readings individual men it is a philosophical essay of cultural interpretation, which seeks to highlight the philosophical and artistic splendors of Ecuador from a symbolic hermeneutics. Highlighting the contributions in understanding the universality of Ecuadorian and Latin American man keeping a humanism that reinterprets the cultural past portraying characters of thought and art that left an impression of universality and comprehensive versatility that catapult as poetic hermeneutics of the Latin America culture, questioning and rethinking the universal pseudo - history of Eurocentric bias. The thinker Benjamín Carrión, the poet Jorge Carrera Andrade and the colonial Caspicara sculptor. Great exponents of the original and transcendent spiritual mindset. The show us what to do in their deep sources of an actively constructive culture and aesthetics source.

Keywords: Mircea Eliade, Benjamín Carrión, myth, homeland, eurocentrism, reductive hermeneutics. 
Larga, compleja e irresoluta hasta el momento ha sido la intención de encontrar un derrotero hermenéutico propio en el Ecuador y América Latina. Aún el problema central del mestizaje, que ha caracterizado a la configuración cultural latinoamericana, sigue siendo identitario. Y quizás el problema central gravita en la manera de entender los procesos latinoamericanos desde lentes y miradas ajenas, sin comprender a cabalidad la realidad propia, sino de manera ecléctica, aplicando teorías construidas para tiempos y espacios diferentes, como estratagemas para solventar un supuesto subdesarrollo. $\mathrm{Y}$ enfatizamos el supuesto, porque la noción de desarrollo científico técnico en la que el Occidente tardo-moderno se embarcó, es un tren de progreso que está desacelerando porque llegó a la final del riel.

Las pretendidas "sociedades del bienestar" se construyeron sobre cimientos de destrucción en otras latitudes. En las últimas décadas las sociedades del bienestar se consumen, para solventar el tráfago de su vida acelerada, el $80 \%$ de la producción mundial. Y es que la dependencia tecnológica, económica, pero sobre todo mental de los latinoamericanos frente a Europa y Norteamérica, no nos ha permitido mirar sobre nosotros mismos, y hemos sido eco activo de equívocos históricos que se han anquilosado por siglos en nuestras prácticas y sobre todo en nuestras mentalidades.

Ya Enrique Dussel ${ }^{1}$ llama la atención sobre esta dependencia eurocéntrica, fijada en la idea desacertada de que en la historia universal, Europa ha jugado un rol central. Y la

\footnotetext{
${ }^{1}$ Se puede consultar 1492. El encubrimiento del otro. Hacia el origen del mito de la modernidad. La Paz, Plural Editores, 1994.
}

producción de conocimiento ilustrado, que sustenta un racionalismo desbordado ha repetido de manera incesante y sin clara conciencia, ideas en las cuales los americanos y sobre todo los latinoamericanos, nos hemos empeñado en creer, pese a la distorsión que han hecho con la historia del "Nuevo Continente".

Según los filósofos alemanes Kant y Hegel, la historia en su trayecto teleológico, ha encontrado destino final en la conciencia que comprende el qué hacer de la manifestación del espíritu absoluto, como lo quiere Hegel. Este espíritu llegó a una madurez en la Ilustración, según Kant, en la que los pueblos antiguos e infantiles, premodernos y, si es posible pensar una barbaridad tal, pre-racionales, han quedado atrasados, ligados a un subdesarrollo, producto del escaso o nulo despliegue de la razón para comprender la realidad. A diferencia de Europa y luego Norteamérica, en donde los seres humanos, por alguna condición particular de la geografía -estamos irónicamente tentados a decir- han desarrollado la razón, y por ende, las aplicaciones de ella para la "modernización" a nivel de la ciencia y la técnica. El conocimiento al servicio del desarrollo productivo.

Es esta irrealidad la que ha permitido la generación de un conocimiento paradigmático, al cual de manera extraña nos adherimos los latinoamericanos sin mirar las consecuencias y dejando de lado la realidad circundante, para vivir otras historias y otras realidades que se sustentan negando la historia y la cultura latinoamericana.

Es así que hemos construido las mallas curriculares en colegios y universidades con la ideas de una historia equivocada. Se nos enseña "Historia Universal", pero esa es la historia particular de Europa, que 
poco tiene de universal, porque de partida excluye lo que no sea relevante en su desarrollo. El historiador norteamericano Charles Mann, comenta que el mundo por cada 100 páginas que se escriben sobre historia, tan solo 4 se escribe sobre la historia americana, remarcando la deuda que los americanos tenemos con nuestro pasado. Esa conciencia lo llevo a escribir 1491. Una nueva visión de las américas de Colón. Importantísima investigación que muestra realidades sorprendentes sobre el pasado pre-colombino americano, señalando los avances científicos y estéticos que habían logrado en su propio proceso histórico. ${ }^{2}$

"En lo que se refiere a sus elementos, América no ha terminado aún su formación. América es, por consiguiente, la tierra del futuro. En tiempos futuros se mostrará su importancia histórica. Más como país del futuro América no nos interesa, pues el filósofo no hace profecías". Este es el argumento de Hegel en sus Tesis sobre filosofía de la historia universal, en relación a América, una América sin importancia y fuera de la historia, es el preciso contexto, donde las nociones históricas y las divisiones temporales se muestran antojadizas $y$ chauvinistas. Por ejemplo, cuando los libros de historia universal narran la historia medieval, por una extraña razón hegeliana, nunca mencionan los hechos que en esa misma época se daban en América. Es como si la edad media como temporalidad o época, de pos sí excluyera a América, la misma que no se sustentaba, por ejemplo, sobre un régimen feudal, ni estaba dividida hostilmente, como sí las poblaciones europeas. Y tal es la miopía hermenéutica, que inclusive pretendemos utilizar las mismas categorías y los mismos presupuestos teó-

\footnotetext{
${ }^{2}$ Charles C. Mannn. 1491. Una nueva visión de las Américas antes de Colón. México, Ed. Taurus, 2006 .
}

ricos para entender la historia prehispánica de América, desde miradas que se han ido enfocando sobre un modelo eurocéntrico excluyente. Una hermenéutica alienada y auto excluyente han manifestado muchos pensadores en Latinoamérica durante décadas.

Son quizás las "hermenéuticas reductivas", como las llama Gilbert Durand a las visiones que han totalizado líneas interpretativas del freudismo y el marxismo, las que más se han alejado y las que han sepultado las posibilidades de interpretación de nuestra historia y nuestras mentalidades desde una vertiente propia. $Y$ no porque la vertiente propia sea válida per se, sino que resulta casi imposible, estéril e infructuoso entender nuestra biografía, estudiando la vida del vecino, por muy interesante que sea.

Tan hondo y profundo ha calado ese menoscabo histórico que hemos pasado décadas pensando si los latinoamericanos tenemos pasado propio, si tenemos ciencia o filosofía. Aún los "académicos" no resuelven si las expresiones de un chamán, un amauta o un tlamatine ${ }^{3}$ son filosóficas o aún pertenecen a una suerte de pre-logos, que ha caracterizado a la historia de la filosofía en Europa. Aún nos negamos a creer que hubo en Quito durante la Colonia una escuela de arte original que lleno de obras a América durante tres siglos, desde Chile hasta México. ¿Habrá filósofos, científicos y artistas en América? Es una pregunta que parece retórica y hasta ridícula, pero aún creemos que artistas, filósofos y científicos verdaderos se dan únicamente

\footnotetext{
${ }^{3}$ Existe un extraordinario estudio que muestra la trascendencia de la poética de filosófica náhuatl, de Miguel León Portilla. La filosofía náhuatl. Universidad Nacional Autónoma de México, México, 1993.
} 
en las sociedades del bienestar. Prejuicio que no nos ha permitido ver el esplendor cultural sobre el que hemos ido haciendo, de manera casi inconsciente, nuestra historia como latinoamericanos, cuyo pasado sí es universal.

Es por ello que vamos a emprender un estudio desde una lente universal, trascendiendo la métrica racionalista, y nos enfocamos a interpretar la poética de las ideas, en tres pensadores ecuatorianos. Un filósofo del arte, un poeta y un pintor. Universos culturales y epocales diversos y de conjunciones, que intentaremos retratar, como ellos a su manera también lo hicieron.

Es en su vida y en su obra que encontraremos a personajes trascendentales, que rompen las hermenéuticas reductivas y nos muestran el pensamiento estético en Ecuador.

Pensamos que el modo más idóneo para estudiar la construcción universal de América Latina, es utilizando modelos integrales de reflexión, como la hermenéutica simbólica, bajo cuyo manto vamos a re-leer a tres pensadores: Benjamín Carrión, Jorge Carrera Andrade y Caspicara.

La poética nos permite salir de los márgenes de la filosofía y a través de una visión de síntesis integrar el pensamiento ecuatoriano al pensamiento universal. La poética, heredera de la poiesis, es el sentido mismo de la creación. Este acercamiento ensayístico es poético en ese sentido, y también porque permite mirar la poética de la historia en el Ecuador.

\section{I.Mito y poética en Benjamín Carrión}

Existe la idea general que la noción de mito o los mitos son una mentira o una cons- trucción falsa sobre la realidad, que la mentalidad del ser humano arcaico creó para poder entender el mundo. De allí que hayan, según estos criterios, creado un universo ficticio de imágenes animistas que derivarían en un literatura ilógica, incomprensible e irracional reflejada en los textos sagrados y en toda manifestación mágico-religiosa. Inclusive la psicología denomina mitomanía a la manía de mentir.

Debemos a uno de los máximos historiadores e intérpretes de las religiones, el rumano Mircea Eliade, el desmentir tal juicio apresurado sobre la mentalidad del hombre arcaico y sobre la verdadera naturaleza simbólica de los mitos y ritos religiosos. Es Eliade quien afirma que la definición de hombre debería ser no como un sapiens sapiens, sino como religiosus, el homo religiosus.

$Y$ es que en efecto, el mito no es una mentira fantástica sobre lo real, sino más bien la forma poética a través de la cual el ser humano estructura un mundo de significados y sentidos desde un perspectiva trascendental, y no como una mera visión pragmática de la vida y sus distintas expresiones.

Es en el mito particularmente, en donde el ser humano arcaico encuentra el valor esencial de su naturaleza sagrada; es justamente en sus mitos donde está construida su psiquis y su cultura; es ahí donde el hombre tiene un sentido, en ese cosmos que es la realidad mitificada. El mito no es mentira, sino el plano de realidad metafísica en el que tienen su verdadero sentido y significado los símbolos; no acontece en el terreno de los hechos físicos y materiales, sino más bien en un cuerpo mental sutil, que sirve como una especie de espacio o geografía espiritual, en donde el ser hu- 
mano asienta su ser y su visión de las cosas. El mito no encubre los hechos con alegorías, sino que muestra la verdad de manera poética, literaria. Sin embargo, este mundo de símbolos que son los mitos, no es un mundo falso, sino que su verdad corresponde al nivel de las ideas. ${ }^{4}$

Benjamín Carrión (1897-1979) comprendió esta verdad del mito -quizás en las mismas épocas en que Mircea Eliade escribiera el resultado de sus investigaciones- y lo planteó como un pilar fundamental para la comprensión de la cultura en general y de la historia cultural de América Latina y del Ecuador en particular. El cuento de la Patria (1967), un libro clásico ya de su pensamiento, es la interpretación más aguda y penetrante que se ha hecho de nuestra cultura, desde una dimensión universal, en donde Carrión transpone nuestra historia cultural en paralelo con los acontecimientos fundamentales de la Historia Universal. El cuento de la patria plantea desde su título un juego semántico, que deja en entre dicho la misma idea de Patria, el cuento de la patria también se podría leer como: la patria es un cuento; manera encubierta de decir cómo la Patria que hemos construido es una construcción simbólica e imaginaria. La verdadera patria es un cuento, un mito, un relato, en su sentido real y positivo, un relato creador de un mundo de

4 Sobre este tema se pueden consultar las diversas obras de Mircea Eliade, especialmente: Historia de las creencias y de las ideas religiosas, 4 volúmenes. Ed. Herder. Barcelona 1996. El mito del eterno retorno. Ed Alianza. Barcelona. 1994. Tratado de historia de las religiones. Ed. Biblioteca Era. 1996. El chamanismo y las técnicas arcaicas del éxtasis. Ed. Fondo de cultura económica. Madrid. 1996. Herreros y alquimistas, Madrid, Ed. Alianza, 1996. significaciones. Carrión afirma que la primera historia del Ecuador es una novela (refiriéndose a la Historia del Reino de Quito del padre Juan de Velasco), por ello la historia del país solo puede contarse noveladamente.

Carrión plantea la idea de que pequeñas naciones en condiciones geográficas adversas, han desarrollado unas culturas que han sido pilares para la historia de Occidente. Léase los griegos y los hijos de Israel. La una en medio de los Balcanes, dio nacimiento a la filosofía europea, la otra asentada en el desierto permitió desarrollar el amor espiritual como fuente del encuentro humano. $\mathrm{Y}$ son justamente esas pequeñas patrias las que han sustentado su esencia cultural en sus mitos. ¿Quién pondría en duda y buscaría si el mito de Moisés es verdadero en el plano de los hechos materiales, para así dar valor a la historia judeocristiana? ¿Cómo podríamos entender el relato de una loba amamantando a unos gemelos y contar desde ahí la historia de Roma? Y sí eso es así, ¿por qué negar nuestros gigantes y nuestras amazonas?, dice Carrión, aludiendo a los mitos contados por Juan de Velasco en su historia del Reino de Quito.

"La poesía suministra a la historia una imagen de lo que es eterno en cada pueblo". Con esta frase del gran historiador Jacobo Burckhardt, abre Benjamín Carrión su cuento de la patria, manifestando como la esencia histórica de un pueblo, quizás no nos la muestre la ciencia histórica, sino el mito, el mito entendido como creación poética que "suministra una imagen de lo eterno en cada pueblo".

"Declaro que al hablar de la fábula, mito o leyenda, estoy hablando a la par de poesía. Porque esas formas de hacer y vivir, de 
pervivir y cantar de todos los pueblos, son la más profunda y alta al mismo tiempo, expresión poética del hombre". ${ }^{5}$

Esta dimensión poética de Carrión no es antojadiza, es el resultado de haber comprendido una misión cultural personal y colectiva, influencia directa de lo que el filósofo mexicano José Vasconcelos planteara en su Raza Cósmica, llegando a encarnar el ideal latinoamericano que tipifica Vasconcelos en su célebre ensayo, como modelo cultural de síntesis; la cultura de la síntesis es la cultura futura latinoamericana, que en su mestizaje ha sabido incorporar a las otras culturas del mundo. El hombre ideal latinoamericano encarna al hombre universal. $Y$ es justamente Carrión quien decide llevar a cabo este ideal en el mundo de las ideas que construye en sus obras, así como en su misión de gestor cultural.

"El objeto del continente nuevo y antiguo es mucho más importante. Su predestinación obedece al designio de construir la cuna de una raza quinta en la que se fundirán todos los pueblos, para remplazar a las cuatro que aisladamente han venido forjando la Historia. En el suelo de América hallará término la dispersión, allí se consumará la unidad por el triunfo del amor fecundo y la superación de todas las estirpes." Y continúa Vasconcelos en su Raza Cósmica, "Y se engendrará de tal suerte el tipo síntesis que ha de juntar los tesoros de la Historia, para dar expresión al anhelo total del mundo". ${ }^{6}$ Carrión encarnó de algún modo esta tipología de síntesis universal.

\footnotetext{
${ }^{5}$ El cuento de la patria, Ed. Casa de la Cultura Ecuatoriana, Quito, 2002, p. 9.

${ }^{6}$ La Raza Cósmica, Editorial Purrúa, México 2007, pag. 15
}

"Para acercarnos a este propósito sublime es preciso ir creando, como si dijéramos, el tejido celular que ha de servir de carne y sostén a la nueva aparición biológica. $Y$ a fin de crear ese sentido proteico, maleable, profundo, etéreo y esencial, será menester que la raza iberoamericana se penetre de su misión y la abrace como un misticismo", insiste Vasconcelos.

Con ese "misticismo" encaró Carrión esa gestión cultural que entendía como "iluminar y engrandecer la realidad", en el sentido de otorgarle su dimensión poética. De ahí que haya sido uno de los primeros intérpretes entusiastas de la cultura; y "entusiasta" lo usamos en el sentido que lo comprendían los griegos, como el plano más alto del conocimiento: aquel que se entusiasma con el conocimiento, que goza con el saber.

Benjamín Carrión veía los aspectos luminosos de nuestra cultura o encontraba valores ocultos en terrenos donde otros habrían visto campos infértiles o infecundos. "No hagamos del cuento de la Patria, de la historia de la Patria, algo infecundo y duro, ensangrentado de batallas y de luchas fraternas. Tratemos de crear La Suave Patria, según la expresión del poeta mexicano por excelencia, Ramón López Velarde. Patria que como la madre, despierte y avive el amor de sus hijos, la ternura, el anhelo ferviente de servirla de honrarla y engrandecerla. Que el cuento de la Patria despierte el interés de los niños. Que pueda ser contado por las abuelitas para arrullar el sueño de los nietos. No la Patria terrible, vindicativa, altanera. En cambio sí la Patria segura de sí misma, llena de altivez, fortalecida con su historia limpia".?

${ }^{7}$ El cuento de la patria, p. 20. 
Y más allá de la historia, Carrión veía en la Geografía la respuesta a la realidad cultural ecuatoriana. Carrión gustaba -y el término es usado intencionalmente- usar la frase del filósofo español Eugenio D’ Ors, quién decía: "iAbajo la historia, viva la geografía! No es casual que el segundo libro escrito por Benjamín Carrión haya llevado por título Mapa de América, no por ser un tratado de descripción de relieves, sino por haber hecho un mapeo estético de la cultura hispanoamericana.

"En estos ensayos de incursión a través del espíritu hispanoamericano contemporáneo -dice Carrión en la introducción a Mapa de América- no he querido seleccionar sino PREFERIR. La selección de orden intelectual, es sistemática, clasifica, establece jerarquías de capacidades. La preferencia, más bien intuitiva, es del orden de la sensibilidad, del orden del gusto".

Esta noción de gusto a la que alude Carrión es uno de los elementos sustanciales a los que nuestros pueblos están abocados por su geografía. Carrión retoma la teoría de configuración evolutiva de las sociedades del filósofo Vasconcelos, quien inspirado en las ideas sobre la evolución espiritual de las sociedades orientales, encontró la teoría que permite comprender una estructura común en su desarrollo. Toda sociedad pasa por tres estadios: el primero tiene que ver con lo económico y militar; el segundo aspecto que debe desarrollar una sociedad que ha logrado solventar su seguridad económica y territorial, tiene que pensarse a sí misma y administrarse, plano que Vasconcelos Ilama intelectual-político y el tercer estadio es cuando la sociedad puede dedicarse a la contemplación, al gusto. La construcción social desde el plano del gusto va más allá de los fines pragmáticos, y se ma- nifestada en la dinámica del cambio cultural.

Vasconcelos dice a este respecto lo siguiente: "se buscará en el sentimiento creador y en la belleza que convence. Las normas las dará la facultad suprema, la fantasía; es decir se vivirá sin norma, en un estado en que todo cuanto nace del sentimiento es un acierto. En vez de reglas, inspiración constante. $Y$ no se buscará el mérito de una acción en su resultado inmediato y palpable; ni tampoco se atenderá a que se adapte a determinadas reglas de la razón pura; el mismo imperativo ético será sobrepujado y más allá del bien y del mal, en el mundo del pathos estético, solo importará que el acto, por ser bello produzca dicha. Hacer nuestro antojo, no nuestro deber; seguir el sendero del gusto, no del apetito ni del silogismo; vivir el júbilo fundado en el amor..." "Vivir en pathos, sentir por todo una emoción tan intensa, que el movimiento de las cosas adopte ritmos de dicha..."; "la voluntad se hace libre, sobrepuja lo finito, y estalla y se anega en una especie de realidad infinita; se llena de rumores y de propósitos remotos; no le basta la lógica y se pone las alas de la fantasía; se hunde en los más profundo y vislumbra lo más alto; se ensancha en la armonía y asciende en el misterio creador de la melodía; se satisface y se disuelve en la emoción y se confunde con la alegría del Universo; se hace pasión de belleza". ${ }^{8}$

Es el trópico es la geografía propicia para la imaginación creadora, para la contemplación, para el gusto. Gabriela Mistral -con quien Benjamín Carrión mantendría una relación de profunda amistad durante décadas- cuando recién conocía al ecuatoriano, realiza el prólogo a su primer libro

\footnotetext{
${ }^{8}$ La raza cósmica, p. 25
} 
Los creadores de la nueva América. En esa introducción Mistral dice respecto del trópico, que éste es el "cielo verdadero", el único "cielo-cielo". Carrión, Mistral, Carrera Andrade, comparten la idea de Vasconcelos, de que así, como las primeras civilizaciones salieron del trópico, es normal que vuelvan a él. El hombre del trópico cuando dominé su entorno a través del conocimiento, formará las bases de una sociedad futura.

Carrión se sintió en el deber histórico de posibilitar el ideal del hombre cósmico vasconceleano. Un hombre de acción cultural que descubre sus fuentes históricas prehispánicas. Esta idea capital llevo a Carrión a publicar una de sus obras mejor logradas: Atahuallpa. Y es este conocimiento de los orígenes el que da importancia a una historia cultural de valores constructivos, y que lleva a Carrión a la creación de su obra más emblemática: La Casa de la Cultura Ecuatoriana.

La Casa de la Cultura Ecuatoriana, obra insigne que ha marcado más de 60 de años de cultura en el Ecuador. Fue creada a partir del conflicto limítrofe en que el Ecuador perdiera una extensa parte de su territorio en 1941 con el Perú. Carrión toma de Keyserling, a través de Mariano Picón-Salas, la teoría de la "fecundidad de lo insuficiente" y la liga a la teoría del "sauce podado" del historiador A. Toynbee. El sauce podado crece más, y lo insuficiente, planteado en términos políticos, lo transmuta Carrión en fecundidad, fundando así la institución cultural más emblemática del Ecuador del siglo XX.

Lástima que en esta misma institución por él fundada, sus obras completas hayan sido quemadas por fanáticos, quedado en las cenizas, y por más de 4 décadas permane- cen aún en el olvido. El pensamiento de Benjamín Carrión es un mito viviente. Un misterio de la síntesis poética filosófica de la América Latina unida por la sabiduría.

\section{Jorge Carrera Andrade: la poética pla- netaria de la unidad}

Reflexiones, indagaciones y retratos, ${ }^{9}$ es el título del libro que Alejandro Querejeta ha compilado con tan admirable juicio, para poder apreciar en una publicación única la trayectoria ensayística del poeta Jorge Carrera Andrade. No es casualidad que sea el ensayo la herramienta que los escritores ecuatorianos han elegido para crear las dimensiones profundas de la cultura y a partir de ella derivar en un conocimiento de sí mismos. Es Baudelaire quien señalaba que es el ensayo la mejor forma de expresión para captar el espíritu de una época, porque se encuentra entre la poesía y el tratado. Morin, por su parte agrega: "el ensayo abriga su sentido y su valor en la proximidad de lo viviente".

$Y$ es que el ensayo se ha constituido como una de las formas creativas más influyentes en el pensamiento latinoamericano, precisamente por permanecer fuera de los márgenes de sistemas filosóficos cerrados. El ensayo muestra la permeabilidad que caracteriza a las culturas herederas del mestizaje y que le confiere esa capacidad particular de pensar desde la síntesis, o como dice Carrera Andrade, desde la "amalgama cultural”. Benjamín Carrión afirmaba que el ensayo, es el aporte de América Latina a la literatura universal, por su alto contenido, plástico, maleable, poético.

\footnotetext{
${ }^{9}$ Jorge Carrera Andrade, Reflexiones indagaciones y retratos, Quito, Ed. Centro Cultural Benjamín Carrión, 2012.
} 
Carrera Andrade es uno de los creadores latinoamericanos más importantes del siglo XX. Su dimensión universal como le calificara Rodríguez Castelo, no es una metáfora grandilocuente que pretende sobre dimensionar al poeta, al contrario, se sustenta en la construcción consciente y activa de una dimensión humana universal, y por ello unifica una identidad humana general, una ciudadanía del mundo, una humanidad planetaria.

Desde su muy temprana juventud, cuenta Carrera Andrade en Edades de mi poesía, ensayo auto reflexivo que abre esta Edición, como al salir del Ecuador descubre al hombre nómada: “Entonces se me reveló la poesía del viaje y me inicié en la magia verde de la geografía".

Esta será una condición existencial del poeta, esta particularidad de ser un hombre en una suerte de destierro metafísico que decide conocer el mundo, penetrando en las ciudades centrales que congregaban a lo más alto del pensamiento en países de oriente y de occidente; permitiéndole vivir los acontecimientos históricos más relevantes del siglo, de los cuales supo extraer la esencia, la belleza del mundo que construye Carrera Andrade en su topos poético.

Su poesía y por ende su condición existencial revelan al hombre que no es ni de oriente, ni de occidente, el hombre como sentido universal... el hombre planetario. Hacia 1959 configura su conjunto poético Hombre Planetario, en dónde manifiesta esta revelación profunda de la unidad humana, como un "forastero perdido en el planeta":

Amigo de la nubes forastero perdido del planeta entre piedras ilustres, entre máquinas reparto el sol del trópico en monedas.
Mercaderes de avispas:

Soy hombre de los trópicos azules. Os espío por cuenta de la luna.

Soy agente secreto de las nubes. ${ }^{10}$

Este "amigo" y "agente secreto de las nubes", al recorrer el mundo constataba las distintas formas de manifestación humana planetaria, en el lugar mismo de los acontecimientos; en Paris, dónde vivió largos años de su vida, dentro de los círculos culturales y cumpliendo una diplomacia cultural, y como poeta, ensayista, traductor, gestor cultural, traba amistad con lo más representativo del pensamiento de la época, sobre todo en lo que a producción poética se refiere. En su viaje a oriente se radica por algunos años en Japón, lo que enriquece su perspectiva cosmopolita de viajero del mundo. En el poema Hombre de cualquier tierra resume el encuentro de un hombre del azul tropical:

Hombre de cualquier tierra o meridiano yo te ofrezco la mano:

Te doy en ella el sol americano.

Te doy la brava pluma

Del cóndor, la candela ágil del puma:

Selva y montaña en suma.

Te doy la geografía

Vasta y azul, el día

concentrado en el fruto de ambrosía.

Te doy nuevo tesoro:

El pimiento y el toro

y la cúpula de oro.

Te doy volcán y rosa, la clave de esa gente misteriosa que en vasijas reposa.

Mi mano es de alfarero, solar, de navegante, misionero y libre guerrillero.

Mano de constructor de un Continente,

${ }^{10}$ La obra poética completa de Jorge Carrera Andrade se encuentra editada por la Casa de la Cultura Ecuatoriana en 1976. 
mano de techo y puente

y alfabeto de amor para la gente.

\section{El sol americano}

te lo entrego en mi mano,

hombre mundial, mi hermano.

Carrera Andrade construye la visión poética del hombre total del que hablaba el hermetismo, y este es un de los elementos más nodales de su poética, como unidad trascendental. Su visión planetaria de la unidad universal es una intuición del advenimiento de esta época para América Latina, que como dice Raynaud de la Ferrièr, está "destinada al más brillante porvenir". ${ }^{11}$ Es época no de la estrechez de la división política, sino de la integración mundial. Carrera Andrade, testigo de la decadencia de occidente, plantea en su intuición un hombre unitario, no el ideal de globalización sino de la planetarización. Es necesario aclarar, dice Edgar Morín, "que el término planetarización es un término más complejo que globalización, porque es un término radicalmente antropológico, que expresa la inserción simbiótica, pero al mismo tiempo extraña, de la humanidad en el planeta Tierra. Porque la Tierra no es solo un terreno donde se despliega la globalización, sino una totalidad compleja física-biológica-antropológica. Es decir, hay que comprender la vida como emergente de la historia de la Tierra y a la humanidad como emergente de la historia de la vida terrestre. La relación del ser humano con la naturaleza y el planeta no puede concebirse de un modo reductor ni separadamente, como se desprende de la noción de globalización, porque la Tierra no es la suma de elementos disconjuntos: el planeta físico,

${ }^{11}$ Sobre el pensador de la Matesis, Serge Raynaud de la Ferriere, y su obra de síntesis se puede consultar Los propósitos psicológicos, México, Ed. Diana, 1978; El arte en la nueva era, Ed. Diana, 1982; Yug, Yoga Yoghismo. Una matesis de psicología, Ed. Diana, 1974. más la biosfera, más la humanidad que debe concebirse como una entidad planetaria y biosférica". ${ }^{12}$

La intuición poética de Carrera Andrade le permite pre-ver lo que vendría en nuestra época como posibilidad del desenvolvimiento humano en el planeta. Esta intuición de la unidad universal, muestra como el arte busca y refleja la verdad en la imaginación creadora, profecía inconsciente del Nuevo Mundo de la complejidad.

Veamos como lo plantea en Edades de mi poesía:

\section{“El cántico de la unidad universal}

El hombre lleva consigo una reunión de seres humanos. Un hombre es siempre plural. Es él y además los otros. Pero, asimismo, un conjunto de experiencias de otros seres y cosas. Este descubrimiento lo hice en el curso de una tentativa de un "viaje al fondo de la tierra" y un viaje "al fondo del hombre". Mi hábito de las profundidades me conducía insensiblemente a considerar la luz como el supremo bien. La luz contenía la clave de la existencia terrenal. Cada día era en sí el fruto de un combate en que la luz sale victoriosa de la sombra. De este convencimiento nació mi poema, Las armas de la luz, en el cual intento explicar la escala de la evolución terrestre:

\section{Amistad de las cosas y de los seres, en apariencias solos y distintos, pero en su vida cósmica enlazados}

\footnotetext{
${ }^{12}$ Edgar Morín, "Los desafíos de la era planetaria”, en Educar en la era planetaria, VV.AA, Quito, Grupo Santillana, 2002.
} 
en oscura, esencial correspondencia más allá de sus muertes, otras formas del existir terrestre..

Todos los seres de agua, tierra y aire especies interinas, vestiduras mortales, sucesivas, de lo eterno.

En la escala que sube del guijarro a la escama, a la hoja y a la pluma, una armonía pávida interroga.

Escuchaba yo la música del mundo, el cántico de la familia universal en la unidad planetaria. La angustia de la muerte se había esfumado ante la certeza de que la vida era una continuidad esencial que no desaparecería, por sus cambios de forma. Comprendí que la muerte no era sino "una diferente manera de vivir".

Esta extensa cita expresa la perspectiva de síntesis que se refleja según Carrera Andrade, por la naturaleza tropical del hombre americano y el carácter de amalgama cultural que caracteriza a este mestizaje.

Esta revelación metafísica de la unidad, emparenta la experiencia poética sagrada de Carrera Andrade con la filosofía peren$n e$, de las filosofías tradicionales.

Esta experiencia arquetípica de la unidad universal y de la luz, fue justamente la que legó el pensamiento persa y luego el islam, cuya poética y sabiduría sirviera de inspiración a Quevedo y Góngora, maestros del epigrama y la saeta, que representan el modelo de la interpretación cultural del poeta y ensayista ecuatoriano, desde el haiku japonés, hasta la historia cultural del Ecuador.

El arquetipo mítico de la lucha de la luz con las tinieblas, lo relatan ya los mitos persas y zoroastrianos. El "Atar" zoroastriano es el fuego -dice Max Muller-, "pero mucho más en su aspecto simbólico, como todo aquello que está definido en el AtharvaVeda. En ese libro-tratado del hinduismo se analiza profundamente la importancia de que el sello de Dios lleve un Sol, Süryashandra-masâbhyâ, ya que su principal cualidad es aquella de aclarar el mundo".

Vemos como la luz, expresada en el símbolo del fuego es una clave simbólica de la mística que viene desde el antiguo Irán persa, el hinduismo, e irá a inspirar la poética sufí y derviche. Es la luz lo que une misteriosamente las cosas. La unidad universal es una identidad luminosa, ligada por el "Atar" zoroastriano.

Es en el sufismo iranio dónde encontramos estos símbolos que entran en este diálogo imaginal simbólico entre la poética sufí y la intuición de la unidad luminosa que relata Carrera Andrade como contenido ontológico del Hombre Planetario. Henri Corbin en El hombre de luz en el sufismo iranio, dice como ésta poética mística medio oriental ha creado "un país sin sombras poblado de seres de luz que han alcanzado alturas inaccesibles a los terrestres". Es en el médium mundi donde se encuentra la naturaleza esencial de la luz y la unidad. ${ }^{13}$

Escuchemos al poeta persa Rumi un fragmento de Las cenizas de la Unión:
Alma mía, tu eres el Fenix que surge de las cenizas de la Unión ¿Por qué no alzar el vuelo? Nadie te reconoce en el suelo.

Es en esta geografía de la luz dónde Carrera Andrade refleja ese antepasado mudéjar que penetró en la poesía hispánica a través

\footnotetext{
${ }^{13}$ Ver, El hombre de luz en el sufismo iranio de Henri Corbin. Madrid, Editorial Siruela, 2000.
} 
de Góngora y Quevedo. Helmut Hatzfeld dice que "tanto el origen como la exageración del barroco en España están en razón directa de ese espíritu mozárabe que, en tiempos pasados, creo el arte mudéjar y la literatura aljamiada". "Dámaso Alonso ha puesto en evidencia -continúa Hatzfeldcómo los poetas arábigo-andaluces extendieron de generación en generación el uso de la metáfora, primeramente abierta, después oculta, y al fin cada vez más complicada, es una continua repetición y variación".

Este hombre planetario "sobre cuyo corazón firman los pueblos un tratado de paz hasta la muerte", ha creado una geografía imaginal, que forma un topos espiritual en el que la imaginación cobra forma, cuerpo, espacio. En la descripción de País sin mapa, Carrera Andrade cartografía una poética del espacio: "Me embarqué, al fin -cuenta en su experiencia poética entre 1938 1940- con rumbo hacia el país que está en todas partes, el país que no tiene mapa porque está dentro de nosotros mismos. Su topografía coincide con los altos y bajos de mi corazón"

\section{Mi vida fue una geografía que repasé una y otra vez libro de mapas o de sueños. En América desperté \\ Una geografía de sueño, una historia de magia fue. Sé de memoria islas y rostros Vistos o soñados tal vez.}

"En el mapa de mi mente Asia era la paciencia, Europa la razón, América la espontaneidad primigenia". "Europa la aristotélica, la luterana, la enciclopédica, la cartesiana, la hegeliana, la administradora de los tesoros del conocimiento y la claridad intelectual del Occidente, era una lúcida creadora de métodos y doctrinas para discipli- nar la inteligencia e interpretar el mundo." "La sapiencia del Asia (...) la certidumbre de la condición pasajera del ser humano ante la duración permanente del mundo. Las generaciones se suceden, las guerras y los cataclismos destruyen millares de vidas, pero el alba vuelve siempre al final de cada noche, como si nada hubiera sucedido. Este hecho coloca la existencia del género humano en un plano cósmico. No somos sino granos de arena de una inmensa Obra que se inscribe en la escala de las constelaciones y galaxias. Esta circunstancia nos enseña una lección de humildad, virtud tan extraña a la civilización de Occidente".

Valor especial otorga Carrera Andrade a América, en la que ve como Vasconcelos, Carrión y Mistral al "continente de síntesis". No es casual que la historia de América sea de algún modo la reunión de la historia de los otros pueblos. Esto lo podemos constatar en el arte colonial quiteño, amalgama preciosa de las artes del mundo. "En el Nuevo Mundo -dice el poeta ecuatoriano- voy a buscar la intuición original, la rica espontaneidad de lo primitivo, la inspiración de las oscuras telúricas que le dan un sentido a la vida del hombre. El hombre es más barro en nuestra América que en cualquier otra parte del mundo". Esta geografía interior culmina en la visión un mundo utópico Aurosia:

\footnotetext{
Todo es oro en Aurosia, el remoto planeta donde las noches áureas son más claras que el día. Los seres que lo habitan, más humanos que el hombre viven en paz, cavando sus auríferas minas.
}

Planeta venturoso. Nuevo Mundo sin fieras ni miedo, sin vejez y angustia de la mente. Jóvenes de cien años, vigorosos y lúcidos en los jardines de oro van a esperar la muerte.

Todo es libre en Aurosia: el agua, el aire, el suelo. Hasta el trigo es silvestre y el pan es para todos. Máquinas silenciosas, andan, cavan, construyen, producen luz, transforman en mil cosas el oro

La distancia entre Aurosia y la Tierra se mide No solo en años-luz a través de la nada 
Sino en años-amor, en siglos de ternura.

No es capaz el terrícola de salvar la distancia

Aurosia, Nuevo Mundo sin ofidios ni felchas:

El gozo de vivir corre en tus manantiales.

Nadie ha visto una lágrima en la historia de Aurosia (Hay una en el museo, convertida en diamante).

Carrera Andrade en su búsqueda poética no ha construido sólo este macrocosmos planetario y universal, sino que en una suerte de dialéctica de la existencia, ha sabido descubrir la particularidad de las cosas, la esencia de las cosas del microcosmos. Su vida campestre desde su niñez le dio la posibilidad de contemplar, no los grandes trazos de la creación universal, sino la minucia y el detalle de los seres pequeños, minúsculos. Se abre así la poética de las cosas y en Mi vida en poemas dice:

"Las cosas en mi mundo poético ocupan un lugar central, son verdaderos personajes en sí mismos y constituyen una forma de expresión del enigma universal que el hombre trata de descifrar. Posición de filosofía animista, muy alejada del menosprecio de los místicos o metafísicos, como el Petrarca que habla de la "miseria extrema de las cosas humanas", o de los escépticos como Quevedo, para quien las cosas son solo "recuerdo de la muerte". Las cosas de mi mundo -por el contrario- viven, palpitan y nos ayudan a comprender la vida".

Y continúa más adelante:

"Mi poesía ha intentado traducir el estado de ánimo de un hombre libre, situado humildemente en medio de las cosas y de un universo cada vez más dominado por la mecánica y la cibernética. Por esta razón alguien ha dicho que aspiro a ser un "San Francisco de
Asís de la Edad Atómica". En realidad, ambiciono únicamente ser un hombre de nuestro tiempo, un testigo insobornable de las derrotas y esperanzas del hombre nuevo, consciente de que en la época de los satélites artificiales queda aún por descubrir una Terra Incógnita: el continente misterioso del corazón humano. Que los ríos de ese Continente enriquezcan con sus arenas de oro a los exploradores de la Nueva poesía de la Edad Futura".

Carrera Andrade descubre en su geografía sagrada, el detalle de las cosas los mundos reducidos que los grandes hechos históricos han querido olvidar. No es casual que esta poética de lo mínimo se haya desenvuelto en medio del descubrimiento de las micro-partículas que componen la materia; el átomo y el quark, son ejemplos claros de estas búsquedas en el microcosmos. El mismo Murray Gell-man (premio Nobel de Física, 1969) confesó haber tomado el nombre de quark, de la novela Finnegans Wake de James Joyce. Así, una rama del conocimiento viene a socorrer a otra...

Esta indagación sobre las cosas le lleva a Carrera Andrade al micrograma, aporte personal inspirado en el epigrama de Quevedo, en las saetas de Góngora y en el hai$k u$ japonés. El micrograma, dice el poeta, "es un trabajo de reducción de lo creado, en pequeñas fórmulas poéticas, exactas, mediante la concentración de elementos característicos del objeto entrevisto o iluminado súbitamente por el reflector de la conciencia. El micrograma es un "instrumento de liberación poética".

Estas últimas afirmaciones del poeta del colibrí, son de pura inspiración del budismo zen. El haikai o haiku en la poética espiritual del Zen es de pura esencia nirvánica, 
heredero del sutra hindú, el koua chino y el koan. Samuel Wolpin dice al respecto del koan en su Diccionario de léxico oriental lo siguiente:

El koan "es un término técnico del budismo zen para denominar a un problema que no puede ser resuelto por la lógica o el intelecto, sino por un choque mental procedente de un nivel espiritual más elevado. Es un ejercicio dado al aspirante para trascender sus limitaciones y desarrollar la intuición".

El micrograma es esta construcción espontánea, que como un estallido, penetra en el sentido oculto de las cosas. No es necesario alejarse de las cosas para penetrar en la esencia de las mimas, es necesario el relámpago de sentido del koan derivado al hiaku y del haiku al micrograma, creación original del poeta ecuatoriano.

"Es en América hispana -comenta Carrera Andrade en El poeta y el mundo material- en donde la poesía abreva en la fuente primera de las cosas sin reflejos lógicos ni metafísicos. El hombre del Nuevo Mundo no sintió en su espíritu los carbones ardientes de la Edad Media y pudo contemplar libremente el fenómeno del mundo material, desplegado con una riqueza sinfónica ante sus ojos".

El poeta ecuatoriano realiza el ideal del hombre total del hermetismo antiguo, la figura del héroe de luz del sufismo iranio, el Al-Insanul Kamil, el hombre universal del islam espiritual, el hombre que descubre que es un pequeño cosmos y que el cosmos es un gran hombre. El poeta de este modo "ordena un universo"
"Hay un matizado y cambiante universo inmediato, compuesto de pequeños seres que nuestra mano puede mover a voluntad y colocar en un orden más o menos armónico. En ese breve universo animado, que me rodeó desde niño, pude señalar mis amistades preferidas y entregarme en una suerte de juego cósmico e intrascendental, aunque significativo.

Así, el colibrí que es un prisma volador o algo como el vagabundo espíritu de los colores, le di por compañía la araña, obrera impaciente y moderadora. $Y$ al ostión, que es la inmovilidad misma, la indiferencia rugosa, informe y esbozada, ante el espectáculo de las cosas, le puse alado del caracol, que es una lección, aunque tímida del esfuerzo y de la marcha. $Y$ al guacamayo de mi Ecuador amazónico le hice que encendiera el fuego del paraíso, como una esperanza, junto a la tortuga, que es la paciencia bruta.

A los buenos seres que expresan su dicha en forma de olor o de aroma, los puse en unión del venado, que es el aprendiz montañés de la ligereza. De la ligereza o velocidad que también es una especie de perfume. $Y$ a los grillos, que observan una disciplina monótona de constructores, le señalé sitio al pie de la palmera arquitectural, verde y sólida tromba del trópico.

Descubrí que los seres feos cumplen también, a su modo, una tarea bella, y que el sapo, el moscardón, el gusano son otras tantas cifras de la clave secreta del universo. La nieve animada del flamenco, la misantropía vegetal del cactus, el trabajo oculto de la oruga en el árbol me condujeron, en as- 
cendente escala cósmica, a descifrar el alfabeto de los pájaros, altos signos que mantienen el orden espiritual del planeta".

Carrera Andrade el creador de los micromundos del hombre planetario, ordena la clave secreta del universo de los seres, cumpliendo la verdadera tarea de "cronista del cosmos".

\section{Trascendencia del arte espiritual qui- teño: la escultura de Caspicara}

Sobre el arte y los artistas coloniales se han tejido interpretaciones, la mayoría, influenciadas por las visiones sobre el rol de la Iglesia en esa época. Para muchos, al hablar de arte espiritual o religioso se produce una mezcla, una confusión con el papel, nefasto en muchas ocasiones, de la iglesia cristiana y sus distintas órdenes durante la Conquista y la Colonia.

Más allá de interpretaciones fragmentadas e ideologizadas, hay una profunda realidad original y trascendente en la producción de los artistas quiteños. Más que meros copistas de pintores y escultores españoles, italianos o flamencos, lo que se produjo en el arte de estas regiones, fue la inspiración en aquellas producciones que del Viejo Continente derivaron hacia América y sirvieron de referente a los artistas quiteños. Más que un adoctrinamiento religioso, donde paganos absorbían inconscientemente el arte cristiano, se generó una sabia y estética asimilación de técnicas y contenidos que se aclaran a la luz del arte tradicional antiguo y medieval. Los códigos modernos de interpretación, ciertamente, escapan a la comprensión del arte sagrado, y vemos como se manifiesta el sentido transcultural.
Una de las condiciones del Arte Sagrado es su autoría anónima, al contrario del arte moderno, donde el autor es preponderante. Al pintor, escultor o imaginero colonial, no le interesaba que su nombre perdure. Le interesaba que su obra sea fiel transmisora de la Idea esencial que deseaba mostrar. Así, la obra se presenta en soporte o base para la meditación espiritual.

Ananda Comaraswamy, historiador del arte y de las religiones y especialista en el pensamiento hindo-búdico, en un ensayo de profunda significación, da el significado de la noción de belleza desde un matiz espiritual, ligado a la más pura tradición. Esta visión del arte tradicional, está emparentada con la perspectiva platónica del arte. Donde la poesía es el elemento central, pero no la poesía como estilo literario sino como expresión de la poiesis en el sentido antes mencionado.

Es la Teoría de la Belleza, A. Comaraswamy explica desde la poética del pensamiento hindú, el sentido de rasa. Rasa es el lado esencial de la poesía, el gusto. "Junto a este término, equivalente a la belleza o la emoción estética (o "encanto") en su estricto sentido filosófico, debemos considerar el adjetivo que de él deriva: rasavant, "dotado de rasa" que se aplica a las obras de arte; también el sustantivo derivado rasika, "el que disfruta de rasa", el conocedor o el amante; y, por último, rasavadana, "saborear rasa", es decir, la contemplación estética." Y continúa: "Para que una obra pueda evocar rasa, uno de los estados de ánimos permanentes ha de constituirse en el modelo rector, al que deben subordinarse todas las demás expresiones de emoción. Es decir, la característica fundamental de una obra rasavant, es la unidad." Unidad que únicamente se percibe desde la empatía. "Rasa se saborea tan sólo por la 
empatía, por Einfühlung, sadarhana en sánscrito, es decir, penetrando sintiendo el sentido permanente de la obra". ${ }^{14}$ Esta empatía es la misma que le inspiró al poeta Carrera Andrade en el hallazgo de este sentido de la unidad.

Caspicara ("piel de palo") (1723?-1796?), seudónimo de Manuel Chili, indio escultor del que hay pocos datos biográficos, representa un modelo clave de la estética colonial americana impregnada de rasa. Su arte sobresaliente -que le valió el título de príncipe de la escultura americana- amalgamó el barroquismo de Durero (de quien Caspicara tomó algunas formas barrocas, en los pliegues y repliegues de sus pinturas), con la imaginería cristiana. El genio indígena estuvo alentado del hondo pasado milenario artístico de su pueblo. Esa amalgama se refleja en la "Sábana Santa", célebre escultura del artista, quien, en vivo realismo místico, muestra la escena espiritual del descendimiento de Jesús de la cruz. Todo el patetismo cristiano se refleja ahí, atestado en las elevadas expresiones de los rostros de los personajes, quienes aparecen absortos el momento en que el Hombre alcanza el absoluto espiritual, que se pliega en cada detalle de la vestimenta simbólica.

Caspicara, comenta fray Agustín Moreno Proaño, es un "hombre de raro talento, se formó en uno de los tantos obradores de escultura que había en la ciudad de aquella época y llegó a poseer el arte de manera asombrosa. Sus obras son de acabada perfección y no se sabe qué admirar más en ellos: si la meticulosa interpretación de los drapeados de sus estatuas o la justeza de formas anatómicas en sus admirables crucifijos. Es el príncipe de la escultura colonial americana, ya por la bondad absoluta

${ }^{14}$ La danza de Siva. Ensayos sobre arte y cultura india, Madrid, Ed. Siruela, 1996. de sus obras, ya por su fecundidad. Descendiente directo de la escuela de talla policroma, no trabajó sino obras religiosas llenas de profundo sentimiento, por lo tanto, marcadas con el elegante barroquismo del siglo XVIII. Es de anotar -eso síque Caspicara, a imitación de los escultores castellanos de los siglos XVI y XVII, hizo de la emoción y del sentimiento el culto de su arte; no hay una sola imagen de este indio famoso que no lleve en sí más que la precisión de las formas, la sinceridad verdadera de las más intensas emociones. Caspicara fue un gran ejecutante $y$, a veces, llegó al virtuosismo, tan delicados son los planos ondulantes de algunas de sus estatuas y tan magníficamente hechos ciertos refinamientos de su modelado".

Las esculturas de Caspicara realizan la encarnación fija del arrobamiento espiritual. El palpable realismo que manifiestan sus piezas hace pensar que los personajes, sus posturas, sus rostros, reflejan un universo inmaterial, fijado en la mirada absorta en la meditación. Son rostros y actitudes que muestran lo que el arte tradicional plantea en su poética.

Muchas técnicas y formas del barroquismo de la época están inspiradas en la metafísica oriental. A. Coomaraswamy, comenta y aclara el vínculo estrecho entre arte y religión: "Religión y arte son dos nombres distintos que aluden a una misma experiencia, a una intuición de la realidad y de la identidad".

Hacia 1924, la nave real Italia llegaba a costas del Ecuador. A bordo, el maestro Julio Aristide Sartorio, realizaba una valoración del arte americano. Al llegar a estas tierras comprobó la trascendencia e importancia del arte quiteño como legado a la historia universal. Sartorio refería el extra- 
ño ambiente indo-búdico que las iglesias quiteñas muestran en los escenarios donde esculturas, pinturas, retablos y templos se asemejaban a construcciones o climas de la India tradicional y su arte. "Los franciscanos, que enviaban sus misioneros hasta el salvaje Japón, importaban a América artífices convertidos, y con la misma maravilla con que hoy en la plástica incaica hallamos documentos patentes del origen mongol, encontramos también en las iglesias de Quito, de Lima, de La Paz, molduras arquitectónicas, cátedras, púlpitos, absolutamente de estilo asiático venidos del lejano oriente. De manera que si las figuras de San Antonio, San Francisco, Santo Domingo, San Francisco Solano, se sustituyeran por las figuras de Brahama, Shiva, Amitabha, Buda, estas se encontrarían en un ambiente familiar" ${ }^{15}$

\footnotetext{
${ }^{15}$ Ver, José Gabriel Navarro, Contribuciones a la historia del arte en el Ecuador. Quito, Trama, 2007.
} 